\title{
A STUDY OF JOHNSON'S FORMULA- SYMPHYSIOFUNDAL HEIGHT MEASUREMENT FOR ESTIMATION OF BIRTH WEIGHT
}

\author{
Annapurna Hogade1, Savita Konin², Prachiti Udaykumar ${ }^{3}$ \\ ${ }^{1}$ Associate Professor, Department of Obstetrics and Gynaecology, M. R. Medical College, Gulbarga. \\ ${ }^{2}$ Associate Professor, Department of Obstetrics and Gynaecology, M. R. Medical College, Gulbarga. \\ ${ }^{3}$ Postgraduate Student, Department of Obstetrics and Gynaecology, M. R. Medical College, Gulbarga.
}

ABSTRACT
BACKGROUND
The foetal weight can be estimated by various methods, which have their own advantages and disadvantages. This study was
undertaken with the aim of resolving the controversies, determine the most accurate method to estimate foetal weight.

\section{MATERIALS AND METHODS}

A prospective, observational study was undertaken in the Department of Obstetrics and Gynaecology at MRMC, Kalaburgi, from November 2014 to November 2015. A total of 100 women attending labour room were included as study samples.

\section{RESULTS}

The mean age of the pregnant women had a mean age of $24.7( \pm 3.9)$ and majority were aged between 20 - 25 years. The gestational age of about $62 \%$ among the pregnant women had gestational age of 37.1 - 40 weeks. About $36 \%$ of the babies born to pregnant women had birth weight between 2.5 - 3 Kgs and the birth weight. The predicted weight by Johnson's formula was between 3 - 3.5 Kgs in $38 \%$ of the cases.

\section{CONCLUSION}

This study had shown that clinical methods were able to predict the birth weight in more than $70 \%$ of the cases. Johnson clinical method of estimation of weight study had shown that overestimation of the weight in lower birth weights and under estimation in higher birth weights. Hence, this precludes the results of this study cannot be generalised. But this study was able to bring out important facts about the estimation of birth weight. There is clearly a role for clinical estimation of birth weight as diagnostic tool suggesting that clinical estimation (Johnson's formula) is sufficient to manage labour and delivery in term pregnancy. This method of foetal weight estimation is useful particularly in remote areas, where there is shortage of experienced medical personnel and to decide the mode of delivery and place of delivery. Symphysiofundal height measurement continues to be used in many countries on large scale because of its low cost, ease to use and need for very little training.

\section{KEYWORDS}

Johnson's Formula, SFH, Birth Weight.

HOW TO CITE THIS ARTICLE: Hogade A, Konin S, Udaykumar P. A study of Johnson's formula- symphysiofundal height measurement for estimation of birth weight. J. Evolution Med. Dent. Sci. 2017;6(17):1327-1329, DOI: 10.14260/Jemds/2017/288

\section{BACKGROUND}

Birth weight is the greatest single factor, which determines the survival of the foetus. The accurate estimation of foetal weight before delivery helps the obstetrician to decide the mode of delivery and also helps in anticipation of problems and shoulder dystocia during labour. The foetal weight can be estimated by various methods, which have their own advantages and disadvantages. This study was undertaken with the aim of resolving the controversies, determine the most accurate method to estimate foetal weight.

Birth weight is the greatest single factor, which determines the survival of the foetus. It is an important factor for neonatal problems. Accurate estimation of foetal weight is of paramount importance in the management of labour and delivery. Foetal weight is also important in assessing whether

Financial or Other, Competing Interest: None.

Submission 04-02-2017, Peer Review 17-02-2017,

Acceptance 18-02-2017, Published 27-02-2017.

Corresponding Author:

Dr. Annapurna Hogade,

Department of Obstetrics and Gynaecology,

M. R. Medical College,

Kalaburagi.

E-mail: hogade51@gmail.com

DOI: $10.14260 /$ jemds $/ 2017 / 288$

(c) (i) $\$$ the foetus is small for gestational age or large for gestational age in order to have a good obstetrical decision making and also to avoid the intrapartum distress, birth trauma and thereby to reduce the neonatal morbidity and mortality. ${ }^{1}$

The accurate estimation of foetal weight before delivery helps the obstetrician to decide the mode of delivery and also helps in anticipation of problems and shoulder dystocia during labour. The literature available suggests that there has been a marked reduction of perinatal deaths in developed countries (10 per 1000 births in developed countries), even though the perinatal death in developing countries like India remains high (60 per 1000 births). The perinatal mortality can be reduced by early antenatal registration and regular antenatal visits. The estimation of foetal weight before delivery is of importance considering the hazards of low birth weight and macrosomia. ${ }^{2}$

During the last decade, estimated foetal weight has been incorporated into the standard routine antenatal evaluation of high risk pregnancies to decide on the mode of delivery and to anticipate problems during labour. ${ }^{3}$

Tactile technique is one of the oldest methods of assessment of foetal dimensions through the maternal abdomen. This is an intuitive technique, which involves palpation of the foetal parts directly through the maternal abdomen wall to estimate the foetal weight. This method is 
convenient and costless method, but known for its predictive errors especially in large infants. ${ }^{4}$

Other methods include use of abdominal girth, Johnson's formula and Dawn's formula. ${ }^{5}$ The currently available techniques for estimating foetal weight have significant degree of inaccuracy and various studies have been done to compare the accuracy of different methods of estimation. Limiting the potential complications associated with birth of both small and excessively large foetuses requires that accurate estimation of foetal weight occurs in advance of deliveries. $^{3}$

\section{MATERIALS AND METHODS}

A prospective, observational study was undertaken in the Department of Obstetrics and Gynaecology at MRMC, Kalaburgi from November 2014 to November 2015. A total of 100 women attending labour room were included as study samples.

\section{Inclusion Criteria}

- All term pregnancies, 37 - 42 weeks in early labour singleton gestation.

- Cephalic presentation.

- Ultrasound scanning at term.

\section{Exclusion Criteria}

1. Abnormal lie and presentation.

2. Multiple pregnancies.

3. Obvious congenital abnormalities.

4. Polyhydramnios.

5. Oligohydramnios.

6. IUD.

7. Mass per abdomen.

\section{Methodology}

1. Written informed consent and counselling.

2. Detailed history.

3. Physical examination - application of Johnson's formula.

Johnson's Formula for Estimation of Foetal Weight in Cephalic Presentation is as Follows

Foetal weight $(\mathrm{g})=\mathrm{SFH}(\mathrm{cm}-\mathrm{n} \times 155$, where $\mathrm{SFH}=$ Symphysiofundal height and $n=12$, if vertex is above ischial spine or 11 , if vertex is below ischial spine.

\section{RESULTS}

The mean age of the pregnant women had a mean age of 24.7 $( \pm 3.9)$ and majority were aged between 20 - 25 years. The gestational age of about $62 \%$ among the pregnant women had gestational age of 37.1 - 40 weeks. About $36 \%$ of the babies born to pregnant women had birth weight between 2.5 - 3 Kgs and the birth weight. The predicted weight by Johnson's formula was between $3-3.5 \mathrm{Kgs}$ in $38 \%$ of the cases.

\begin{tabular}{|c|c|c|c|c|c|}
\hline \multirow{2}{*}{ Weight } & \multicolumn{2}{|c|}{$\begin{array}{c}\text { Birth } \\
\text { Weight }\end{array}$} & \multirow{2}{*}{$\mathbf{z}$} & \multicolumn{2}{c|}{$\begin{array}{c}\text { Johnson's } \\
\text { Formula }\end{array}$} \\
\cline { 2 - 6 } & Frequency & $\mathbf{\%}$ & & Frequency & $\%$ \\
\hline Less than 2 Kgs & 8 & 8.0 & & 1 & 1.0 \\
\hline $2-2.5 \mathrm{Kgs}$ & 13 & 13.0 & & 11 & 11.0 \\
\hline $2.5-3 \mathrm{Kgs}$ & 36 & 36.0 & & 31 & 31.0 \\
\hline $3-3.5 \mathrm{Kgs}$ & 30 & 30.0 & & 38 & 38.0 \\
\hline $3.5-4 \mathrm{Kgs}$ & 10 & 10.0 & & 17 & 17.0 \\
\hline $4-4.5 \mathrm{Kgs}$ & 3 & 3.0 & & 0 & 0.0 \\
\hline Total & $\mathbf{1 0 0}$ & $\mathbf{1 0 0}$ & & $\mathbf{1 0 0}$ & $\mathbf{1 0 0}$ \\
\hline
\end{tabular}

The symphysis pubis to fundal height in $66 \%$ of the pregnant women was 30.1 - $35 \mathrm{cms}$. The clinical weight estimation by using Johnson's formula was 3144.6 gms and the birth weight was 2978.5 gms to overestimate the birth weight. In neonates weighing less than $3 \mathrm{Kgs}$ and correctly predicted weight for neonates with $36.0 \%$ by Johnson formula had $5 \%$ error in weight estimation. The correlation coefficient between birth weight and Johnson formula weight was $73.8 \%$.

Distribution of the Study Subjects according to Symphysiofundal Height

\begin{tabular}{|c|c|c|}
\hline SFH & Frequency & Percent \\
\hline $25.1-30 \mathrm{cms}$ & 15 & 15.00 \\
\hline $30.1-35 \mathrm{cms}$ & 66 & 66.00 \\
\hline $35.1-40 \mathrm{cms}$ & 19 & 19.0 \\
\hline Total & $\mathbf{1 0 0}$ & $\mathbf{1 0 0 . 0 0}$ \\
\hline
\end{tabular}

Distribution of the Study Subjects according to Symphysiofundal Height

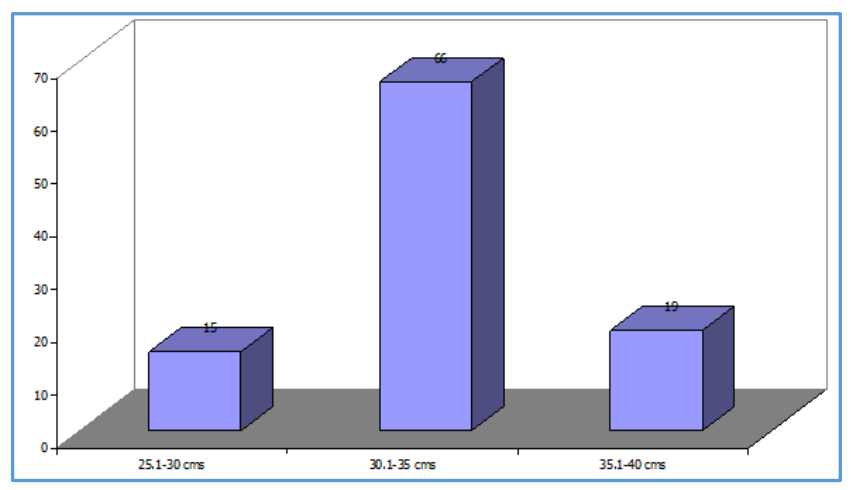

\section{DISCUSSION}

The birth weight is the greatest factor, which determines the survival of the foetus. It is one of the important determinant of neonatal survival. Accurate estimation of foetal weight is of paramount importance in the management of labour and delivery. It mainly helps the obstetrician to decide the mode of delivery and also helps in anticipation of problems and shoulder dystocia during labour. ${ }^{1}$

The literature available suggests that there has been a marked reduction of perinatal deaths in developed countries (10 per 1000 births in developed countries), even though the perinatal death in developing countries like India remains high (60 per 1000 births). ${ }^{2}$ The foetal weight estimation has been incorporated into the standard routine antenatal evaluation of high risk pregnancies to decide on the mode of delivery and to anticipate the problems during labour. ${ }^{3}$

Other methods include use of abdominal girth, Johnson's formula and Dawn's formula. ${ }^{5}$

Currently available techniques for estimating the foetal weight have significant degree of inaccuracy as evident by various studies. Limiting the potential complications associated with birth of both small and excessively large foetuses requires that accurate estimation of foetal weight occurs in advance of deliveries. ${ }^{3}$

In order to resolve the controversies of different methods in weight estimation, this study was undertaken to determine the most accurate method to estimate foetal weight. Thus, it improves the management of labour.

The study had shown that about $43 \%$ of the pregnant women enrolled were aged between 20 - 25 years and $37 \%$ of 
the women were aged between 25 - 30 years. The mean age of pregnant women in this study was lesser in this study compared to other studies. ${ }^{1,6,7,8}$

The symphysis pubis to fundal height was between 30.1 $35 \mathrm{cms}$ in $66 \%, 35.1-40 \mathrm{cms}$ in $19 \%$ and $25.1-30 \mathrm{cms}$ in $15 \%$ of the pregnant women. In a study by Parvin et al, similar results were obtained. About $66 \%$ of the patients had a symphysiofundal height of $31-35 \mathrm{cms} .{ }^{9}$

\section{Estimated Weight by Johnson}

More than $66 \%$ of the pregnant women delivered weighed more than 2.5 Kgs. The predicted weight by Johnson's formula was more than $2.5 \mathrm{Kgs}$ in $68 \%$ of the cases. ${ }^{10}$

\section{Estimated Error by Johnson}

The mean error in clinical estimated weight by Johnson's weight is 141.3 gms. The mean error of difference between the predicted weight and birth weight was higher in lower birth weight groups and negative in higher birth weight groups. This difference in error was statistically significant between the birth weight by Johnson formulae. The mean estimated weight by Johnson formula was $\mathbf{5 7 3}$ gms in a study by Kathiriya et al. ${ }^{1}$

\section{Average Estimated Weight with Birth Weight}

The Johnson formula overestimated the weight of foetus who had birth weight of less than $3 \mathrm{Kgs}$. It correctly predicted the birth in neonates with birth weight of more than 3 Kgs. The difference in predicting the weight of babies and different birth weight groups by Johnson's formula was statistically significant. In a study by Kathiriya et al, 1 the mean estimated weight was 1184 gms, 832 gms, 519.3 gms, 202.5 gms and 131.16 gms in foetal birth weight of $<2 \mathrm{Kgs}, 2-2.5 \mathrm{Kgs}, 2.5-$ $3 \mathrm{Kgs}, 3-3.5 \mathrm{Kgs}$ and $>3.5 \mathrm{Kgs}$ respectively. Study by Alkanash et al, the weight was 2888 gms in foetus with birth weight of less than $3 \mathrm{~kg}$ and 3213 gms in foetus with birth weight of more than $3 \mathrm{Kgs}$. The estimated clinical weight was 3000 gms in neonates with birth weight of less than $3 \mathrm{Kgs}$ and 3635 gms in neonates with birth weight of more than 3 Kgs. 10

\begin{tabular}{|c|c|}
\hline Study & Johnson's Method \\
\hline Gerard et al (2003) & 0.600 \\
\hline Ben-Haroush et al (2004) & 0.775 \\
\hline Kavitha et al (2014) & 0.496 \\
\hline This study & 0.751 \\
\hline
\end{tabular}

The correlation coefficient between the birth weight and Johnson formula estimation of weight was positive and significant at $5 \%$ significance levels. ${ }^{11}$

\section{Over and Under Estimation of the Birth Weight}

The weight was overestimated in $39.4 \%$ of the babies who had birth weight between $2.5-3.0,22.7 \%$ of $3-3.5 \mathrm{Kgs}$ and $19.7 \%$ of the babies with $2-2.5$ Kgs. The weight was underestimated in $44.1 \%$ of the babies of $3-3.5 \mathrm{Kgs}, 29.4 \%$ of the $2.5-3.0 \mathrm{Kgs}$ and $17.6 \%$ of the babies with $3.5-4.0 \mathrm{Kgs}$ by Johnson Formula.

\section{CONCLUSION}

This study had shown that clinical methods were able to predict the birth weight in more than $70 \%$ of the cases. Johnson clinical method of estimation of weight, study had shown that overestimation of the weight in lower birth weights and underestimation in higher birth weights. Hence, this precludes the results of this study cannot be generalised. But this study was able to bring out important facts about the estimation of birth weight.

There is clearly a role for clinical estimation of birth weight as diagnostic tool suggesting that clinical estimation (Johnson's formula) is sufficient to manage labour and delivery in term pregnancy.

This method of foetal weight estimation is useful particularly in remote areas, where there is shortage of experienced medical personnel and to decide the mode of delivery and place of delivery.

Symphysiofundal height measurement continues to be used in many countries on large scale because of its low cost, ease to use and need for very little training.

\section{REFERENCES}

[1] Kathiriya D, Patil Y, Patange RP. Comparative study of various methods of fetal weight estimation at term pregnancies. International Journal of Recent Trends in Science \& Technology 2014;9(3):453-6.

[2] Altenfelder M. Clinical formulas, mothers' opinion and ultrasound in predicting birth weight. Sao Paulo Med J 2008;126(3):145-9.

[3] Hendrix NW, Grady CS, Chauhan SP. Clinical versus sonographic estimates of birth weight in term parturients. A randomized clinical trial. J Reprod Med 2000;45(4):317-22.

[4] Ojwang S, Ouko BC. Prediction of foetal weight in-utero by fundal height/ girth measurements. J Obstet Gynecol East Central Afr 1984;3:111.

[5] Chauhan SP, Hendrix NW, Magann EF, et al. Limitations of clinical and sonographic estimates of birth weight: experience with 1,034 parturients. Obstetrics and Gynecology 1998;91(1):72-7.

[6] Ashrafganjooei T, Naderi T, Eshrati B, et al. Accuracy of ultrasound, clinical and maternal estimates of birth weight in term women. EMHJ 2010;16(3):313-7.

[7] Adam M, Tambul JY, Yousef M, et al. The accuracy of ultrasound in estimation of fetal weight. J Am Sci 2013;9(12):798-802.

[8] Simms-Stewert D, Hunter $\mathrm{T}$, Fletcher $\mathrm{H}$, et al. Comparison of ultarsonographic estimated fetal weight and actual birth weight performed by residents in training at the university of the West Indies. West Indian Med J 2013;62(9):829-32.

[9] Parvin Z, Shafiuddin S, Uddin MA, et al. Symphysio Fundal Height (SFH) measurement as a predictor of birth weight. Faridpur Med Coll J 2012;7(2):54-8.

[10] Alnakash AH, Mandan DR. Fetal body weight: How far the clinical and sonographic estimations can coincide and their correlation with the actual birth weight. Iraqi J Comm Med 2013;2:180-3.

[11] Ben-Haroush A, Yogev Y, Mashiach R, et al. Accuracy of sonographic estimation of fetal weight before induction of labour in diabetic pregnancies and pregnancies with suspected fetal macrosomia. J Perinat Med 2003;31(3):225-30. 